\title{
DYNAMIC ANALYSIS OF TOOL HOLDER WITH DAMPING ESTIMATION
}

\author{
F.R. Gomaa \\ Associates Professor, Faculty of Engineering ,Menoufia University. \\ E-mailfawkiagomaa@yahoo.com
}

\begin{abstract}
This paper presents a new approach to design tool holder subjected to dynamic loads. The aim of this paper is to estimate damping based on experimental and simulated data with high degrees of freedom. Accurate damping ratios were extracted using modal damping based on fitting exponential decays plus subspace model. The data is collected through three fixed accelerometers and one moving, and simulated data using ANSYS. To validate the proposed model impulse excitation plus random excitation were used to fulfill the criteria of output only measurement .The damping matrix was calculated using measured damping ratios to simplify the damping estimation and save time. The main advantage is the degree of accuracy used with respect to the complex mode. This method can be used in higher order frequency and complex structure.
\end{abstract}

Key words: Damping identification, Enhanced frequency domain decomposition, Stochastic subspace identification, Damping measurement and Vibration of tool holder .

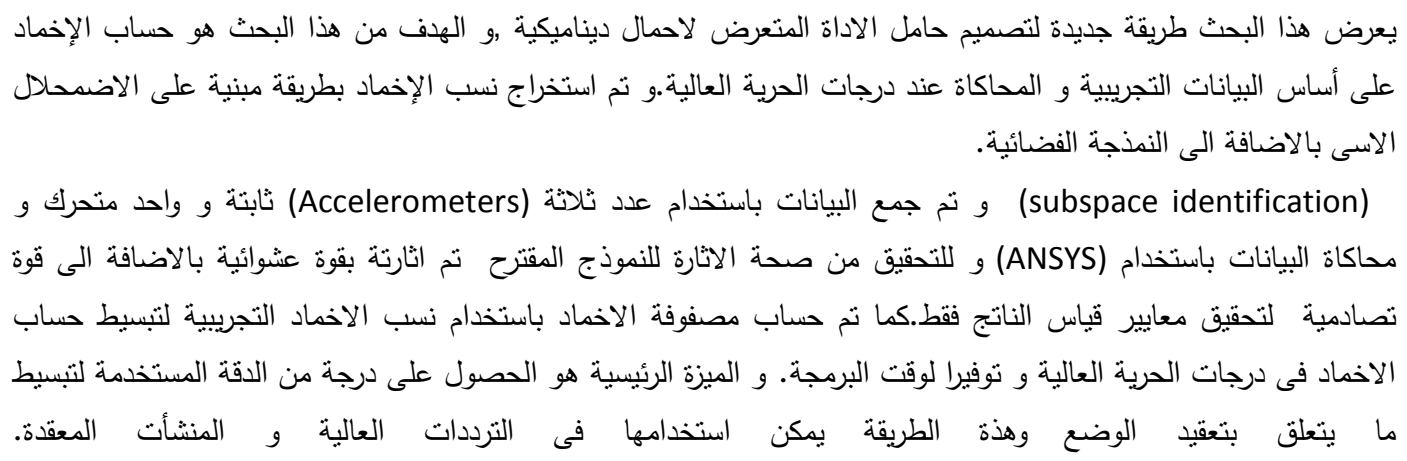

\section{INTRODUCTION}

The surface quality and precision of work pieces depend primarily on a vibration of tool holder used for high speed drilling of work pieces. The problems from vibration lead to reduce tool life according to vibration level. So the common methods used to control vibrations in milling systems utilize the control mechanisms of the cutting parameters related to the machine. Other methods are either based on passive vibration absorption or active control that applies a secondary control force. Several methods have been developed to find cutting parameters that can be used to avoid instabilities [1-4]. The most commonly used method is to change some of the parameters during cutting, i.e., changing the spindle speed or the feed rate of the work piece. The goal to be achieved by changing one of the cutting parameters is to reduce the dynamic feedback into the system and thus to avoid instability. The most common parameter to change is the spindle speed. An example of a passive solution was put in [5]. They presented the development and testing of a tuned viscoelastic dampers in a milling. Active solutions have also been proposed, for example, by J.L. Dohner et al. [6]who developed an active structural control system able to alter the dynamics of the system. Furthermore, active solution based on embedded piezoelectric actuators in a palletized work piece holding system for milling was presented by Rashid et al. [7]. Another active solution focusing on the spindle was implemented by Denkenaet al. who used a contactless magnetic guide in a milling machine prototype to sense and actuate harmonic disturbances [8].From the literature review It appears that little experimental work has been done on the identification of the dynamic properties of the milling tool holder and the spindle house

The damping of the tool holder gives information on how quickly the tool holder dissipates vibration energy and returns to rest when the excitation force is removed. Lightweight structures exhibit less damping than heavy structures, and the system's damping cannot be accurately determined analytically, it must be obtained by measurement. The modeling 
approaches show that spindle dynamics are influenced by a large number of factors, including holder characteristics, spindle shaft geometry and drawbar force, and the stiffness and damping provided by the bearings [9-13]. One of the most amazing achievements in engineering is the practical application of numerical simulation. The characterization of damping is very important in making accurate predictions of both the true response and the frequency response of any device or structure dominated by energy dissipation. However, this parameter is difficult to be estimated analytically. In general, it is very difficult to develop predictive physical model for damping phenomena regarding mechanical structures. This is due to the strong stochastic behavior exhibited by damped mechanical systems. In order to minimize model complexity and enhance model applicability, semi-empirical models are usually preferred to describe the damping coefficient behavior. A well common damping model is that of Rayleigh [14], representing the damping matrix as a linear combination of mass and stiffness matrix, as follows

$$
[C]=\alpha[M]+\beta[K]
$$

Pilkey [15] developed two procedures for the computation of a damping matrix for finite element model updating. Both methods, direct and iterative, are based on partitioning of the inertia and stiffness matrices of the system, and the normalization of the eigenvectors. These methods allow a fast convergence but they need the experimental data to be quite accurate. Characterization of damping forces in a vibrating structure has long been an active area of research in structural dynamics. Despite significant research, however, a thorough understanding of damping mechanism has not been attained. A major reason for this is that the state variables that govern damping forces are generally not as clear as they are for inertia and stiffness forces. There are advanced research results to identify a general model of damping [16] or the estimation of damping in a random vibrating system[17] The most common approach is to use viscous damping or Rayleigh damping, in which it is assumed that the damping matrix is proportional to the mass [M] and stiffness matrices [K].For large systems, identification of valid damping coefficients, $\alpha$ and $\beta$, for all significant modes is a very complicated task. As shown by [18], one could set up a methodology to estimate the Rayleigh damping coefficients that will approximate the damping for all frequency modes in this linear range. The applicability of this methodology was investigated by the author for tool holder. To overcome the limitations of the traditional procedure, due to the fact that, in this method, a model with non-proportional damping is fitted to the data, allowing the identification of closely spaced modes. Furthermore, with this technique, after the identification of the modal properties, it is possible to decompose the measured free decays in modal decays using the well-known decomposition of the output correlation matrix [19]. This paper presents the theoretical basis of tool holder simulation with damping estimation using accurate experimental modal analysis and stability chart. The dynamic behavior of tool holder was discussed using spectrum analysis, operation deflection shape, experimental modal analysis and Finite element modeling.

\section{MATHEMATICAL MODEL TO CALCULATE DAMPING MATRIX}

The equations of motion of a damped system can be obtained through finite element method and gives as

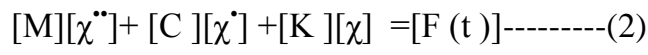

where $[\mathrm{M}],[\mathrm{C}]$ and $[\mathrm{K}$ ]are the mass, damper and stiffness matrices; $\left[\chi^{\ddot{*}}\right]\left[\chi^{*}\right]$ and $[\chi]$ are

the acceleration, speed and displacement vectors and $[\mathrm{F}]$ is the excitation vector. Usually, the values of the elements of $[\mathrm{M}]$ and $[\mathrm{K}]$ are well known. However ,the elements of [C] are difficult to obtain. To estimate the values of the elements of [C], several procedures based on knowledge of the finite element or analytical mass and stiffness matrices and measured Eigen data have been developed. To find the modal parameters several methods are used [20,21]: the rational fraction polynomial method, complex exponential method and Ibrahim time domain method all methods are based on frequency response function between an excitation signal and the measured signal.

An iterative procedure described in [22] can be used to adjust a reduced system of equations .The procedure is based on the partitioned equation of motion:

Where $[\mathrm{M}]$ is the inertia matrix, $[\mathrm{K}]$ is the stiffness matrix, $[\mathrm{x}]$ is the displacement vector, $[\mathrm{F}]$ is the excitation vector, $\mathrm{m}$ are the measured nodal points and $\mathrm{s}$ are the non-measured nodal points.

$\left(\begin{array}{ll}M_{m m} & M_{m s} \\ M_{s m} & M_{s s}\end{array}\right)+\left(\begin{array}{l}\chi_{m} \\ \chi_{s}\end{array}\right)\left(\begin{array}{ll}k_{m m} & K_{m s} \\ K_{s m} & k_{s s}\end{array}\right)=\left(\begin{array}{l}\boldsymbol{F}_{m} \\ \mathbf{O}^{\prime}\end{array}\right)--------(3)$

The reduced system is

$\left[\mathrm{M}_{\mathrm{r}}\right]\left[\ddot{x_{\mathrm{m}}}\right]+\left[\mathrm{K}_{\mathrm{r}}\right]\left[\mathrm{x}_{\mathrm{m}}\right]=\left[\mathrm{f}_{\mathrm{m}}\right]$ $-(4)$

Where $[\mathrm{Mr}]$ and $[\mathrm{Kr}$ ] are the reduced matrices for the first eight modes shapes obtained through 
measurements. From the experimental study the measured modal damping ratios in terms of the discrete natural frequencies can be obtained by Enhanced Frequency Domain

Decomposition(EFDD) And Stochastic Subspace Identification( SSI) as in table (1\&2). Then it is possible to obtain a function of the form (2) using the measured values and substituting in equations (5and 6) to calculate constant $\mathrm{a}_{0}, \mathrm{a}_{1}, \mathrm{a}_{\mathrm{n}}$ and damping matrix. $\xi(\omega)=a_{0}+a_{1} \omega+a_{2} \omega^{2}+a_{3} \omega^{3}+------+a_{n}(5)$ The modal damping constant in terms of the discrete natural frequencies can be obtained $\mathrm{b} \quad 2 \xi \mathrm{i}\left(\omega_{\mathrm{i}}\right)=$ $2 \omega\left(a_{0}+a_{1} \omega_{i}+a_{2} \omega_{i}^{2}+a_{3} \omega_{i}^{3}+----\right.$ $\omega_{\mathbf{i}}{ }^{\mathbf{n}}$

Eq.(6) is a function of $\omega_{i}$ and simply replace $\omega^{2}{ }_{i}$ by $\mathbf{M}_{\mathbf{r}}^{-1} \mathbf{K}_{\mathbf{r}}$ and any constant terms for all frequency modes by constant times I (identity matrix) to obtain the damping matrix in high order:

$$
\mathbf{C}=\mathbf{2 M} \sqrt{M^{-1} K_{r}}
$$

The $\mathrm{n}$ order equation

$$
\begin{aligned}
& {[\mathbf{C}]=\left[\mathbf{a}_{\mathbf{o}} \mathbf{I}+\mathrm{a}_{1}\left(\mathbf{M}_{\mathbf{r}}^{-1} \mathbf{K}_{\mathbf{r}}\right)+\mathrm{a}_{2}\left(\mathbf{M}_{\mathbf{r}}{ }^{-1} \mathbf{K}_{\mathbf{r}}\right)+\right.} \\
& 3 / 2 \quad \mathrm{n} / 2 \\
& \left.a_{3}\left(M_{r}^{-1} K_{r}\right)+----a_{n}\left(M^{-1} K_{r}\right)\right]
\end{aligned}
$$

\section{EXPERIMENTAL SET-UP AND PROCEDURES}

To obtain the experimental data, three accelerometers were used. system was excited though an impact hammer as in Fig.( 1a) and exciter using random force to represent ambient excitation Fig.(1b) .The function FRF was estimated by using different methods of modal analysis Frequency Domain Decomposition (FDD), Enhanced Frequency Domain Decomposition (EFDD) and Stochastic Sub space Identification( SSI) to calculate natural frequencies of structure and accurate damping ratios[23-27].The experimental work with estimated results presented the same behavior with time saving equal $82 \%$. To estimate the damping matrix of the system, the procedure was interpolation of a norder function, Eq.(8),

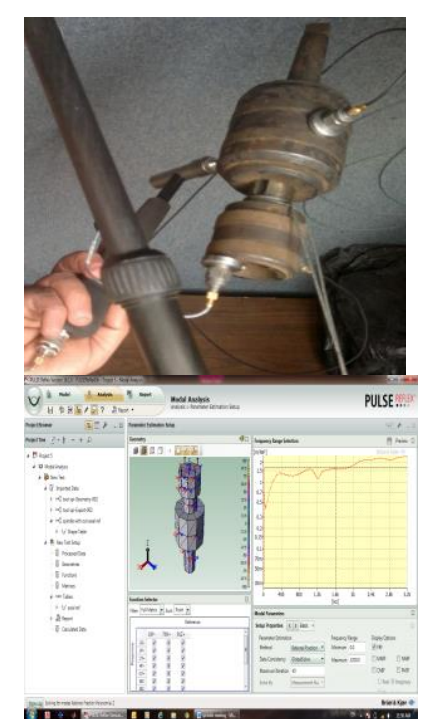

Fig(1a) Free Impact test using impact hammer with fixed three reference accelerometers and moving one.

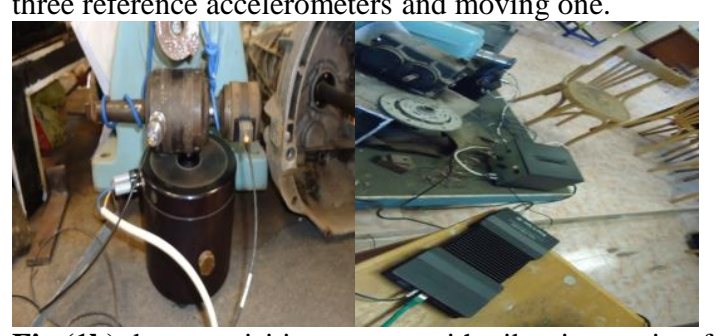

Fig.(1b) data acquisition system with vibration exciter for vibration testing

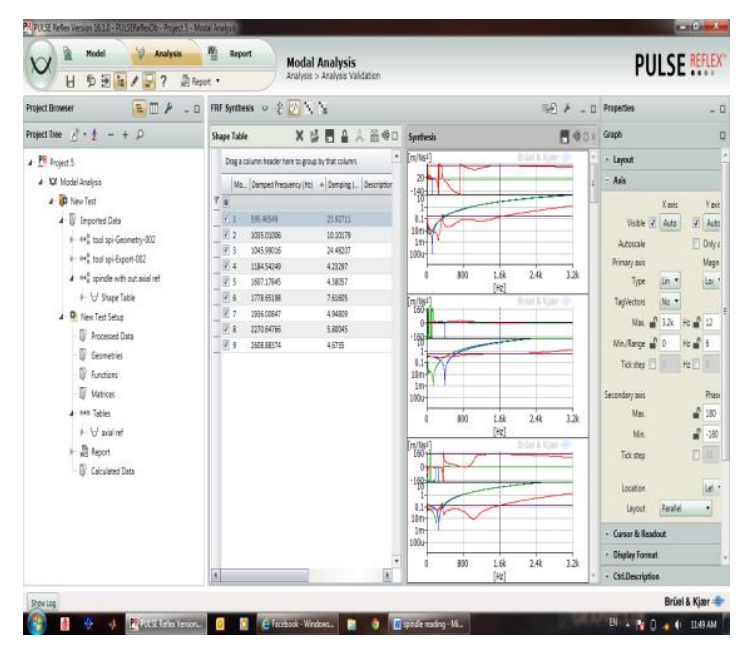

Fig.(2) Sample of FRF Results for tool holder 
3.1 Modal drawing and position for reference sensor and impact hammer

Figs.(3a,b) Show the position of measurements

REFRANCE POSITION

HAMMERING POSITION
Fig,(3a)Position of reference sensor

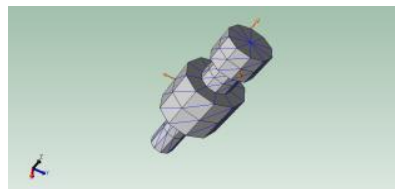

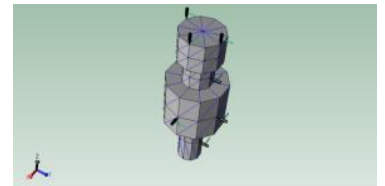

Fig.(3b) Position of impact hammer

\begin{tabular}{|c|c|c|c|}
\hline & $\begin{array}{l}\text { Damped } \\
\text { Frequency } \\
(\mathrm{Hz})\end{array}$ & $\begin{array}{l}\text { Damping } \\
(\%)\end{array}$ & Complexity \\
\hline 1 & 1073.66216 & 8.97582 & 0.17298 \\
\hline 2 & 1218.77783 & 8.16236 & 0.12511 \\
\hline 3 & 1625.14468 & 4.02002 & 0.26432 \\
\hline 4 & 1952.19665 & 4.78210 & 0.57286 \\
\hline 5 & 2291.46811 & 2.64216 & 0.26774 \\
\hline 6 & 2313.69848 & 5.46193 & 0.19150 \\
\hline 7 & 2563.06838 & 8.01002 & 0.30578 \\
\hline 8 & 2662.07407 & 3.20109 & 0.51254 \\
\hline
\end{tabular}

Degrees of freedom (DOF)consist of, Impact Hammer $(\mathrm{B} \& \mathrm{~K})$ roving exciter, with 3 fixed response (references) type B\&K.The measurements were taken using the Brüel \& Kjær PULSE Multi-analyzer system LAN-XI, and theModal Test Consultant to create the geometry, assign the measurement points and directions (DOF's), and capture the data. The analysis was then done using the Brüel \& Kjær software (PULSETM modal analysis In the first measuring 3 references ( 2 at radial and 1 at axial direction).

3.2 Damping measurements based on EFDD method and SSI[17] using exciter to

simulate operation modal analysis.

Figure(4) shows damping with time(see table 1and 2)and mode shape Fig.(7)
Fig(4) Damping with time

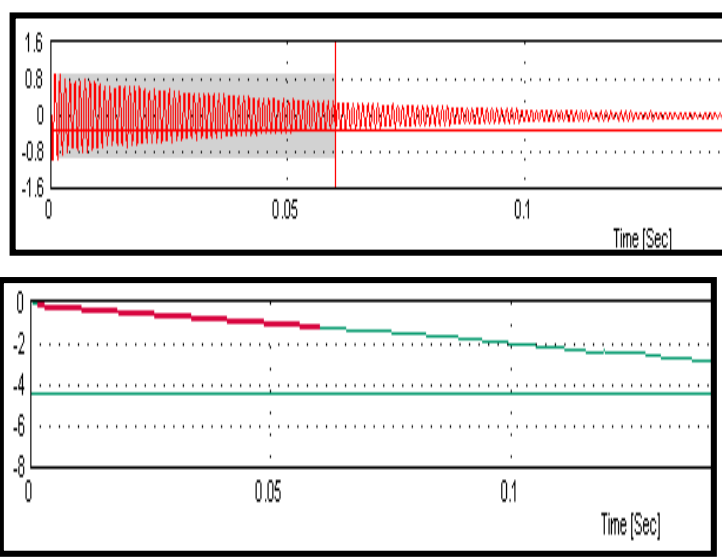

Table(1) Results of EFDD technique for FRF

Table (2) second measurements remove axial reference from calculation for Stability diagram

\begin{tabular}{|c|c|c|c|c|}
\hline $\begin{array}{l}\text { Mode } \\
\text { No. }\end{array}$ & $\begin{array}{c}\text { Frequency } \\
{[\mathrm{Hz}]}\end{array}$ & $\begin{array}{l}\text { Damping } \\
\text { Ratio [\%] }\end{array}$ & Stability & Remarks \\
\hline 1 & 1070.563 & 8.967 & stable & $\begin{array}{c}\text { Found } \\
\text { automatically }\end{array}$ \\
\hline 2 & 1303.271 & 1.100 & Noise & $\begin{array}{c}\text { Found } \\
\text { automatically }\end{array}$ \\
\hline 3 & 1771.875 & 1.065 & Unstable & $\begin{array}{c}\text { Found } \\
\text { automatically }\end{array}$ \\
\hline 4 & 1915.033 & 3.550 & Noise & $\begin{array}{c}\text { Found } \\
\text { automatically }\end{array}$ \\
\hline 5 & 1953.632 & 4.765 & Stable & $\begin{array}{c}\text { Found } \\
\text { automatically }\end{array}$ \\
\hline 6 & 2313.638 & 5.534 & stable & $\begin{array}{c}\text { Found } \\
\text { automatically }\end{array}$ \\
\hline 7 & 2513.1 & 0.7345 & Unstable & $\begin{array}{c}\text { Found } \\
\text { automatically }\end{array}$ \\
\hline 8 & 2661.432 & 3.2352 & Stable & $\begin{array}{l}\text { Found } \\
\text { automatically }\end{array}$ \\
\hline
\end{tabular}

\section{THEORETICAL BACKGROUND FOR FREQUENCY DOMAIN DECOMPOSITION [28-30]}

The relationship between the unknown inputs $x(t)$ and the measured responses y $(\mathrm{t})$ can be expressed as:

$$
G_{y y}(\omega)=H^{*}(\omega) G_{x x}(\omega) H^{T}(\omega)
$$

Where:

$\mathrm{G}_{\mathrm{xx}}(\omega)$ is power spectral density matrix of the input. $\mathrm{G}_{\mathrm{yy}}(\omega)$ is power spectral density matrix of responses. $\mathrm{H}(\omega)$ is frequency response function matrix.

The superscripts "*" and " $T$ " denote complex conjugate and transpose respectively. 
The FRF can be written in pole/residue form as:

$$
H(\omega)=\sum_{k=1}^{n} \frac{R_{k}}{i \omega-\lambda_{k}}+\frac{R_{k}^{*}}{i \omega-\lambda_{k}^{*}}
$$

$$
R_{k}=\phi_{k} \gamma_{k}^{T}
$$

Where: $\varphi_{\mathrm{k}}$ and $\gamma_{\mathrm{k}}$ are the mode shape vector and the modal participation vector for mode $\mathrm{k}$ respectively. Suppose the input is white noise, i.e. its PSD is a constant matrix $\left(\mathrm{G}_{\mathrm{xx}}(\omega)=\mathrm{C}\right)$, then equation (9)becomes:

$$
G_{y y}(\omega)=\sum_{k=1 s=[}^{n} \sum_{[}^{n}\left[\frac{R_{k}}{i \omega-\lambda_{k}}+\frac{R_{k}^{*}}{i \omega-\lambda_{k}^{*}}\right] \times C\left[\frac{R_{s}}{i \omega-\lambda_{s}}+\frac{R_{s}^{*}}{i \omega-\lambda_{s}^{*}}\right]^{H}
$$

Then the pole of the kth mode $p_{k}=-\sigma_{k}+j \omega_{k}$ where $\sigma_{k}$ modal damping of $k_{t h}$ mode, $\omega_{\mathrm{k}}=$ modal frequency of $\mathrm{k}_{\mathrm{th}}$ mode $*$ denotes complex conjugate $\mathrm{j}$ denotes the imaginary operator. System order and stable poles can be found in stability diagram Fig.5which provide modes of the structure for multi order system identification with high accuracy compared with EFDD[26]. It is an important tool is used to assist the user in separating physical pole from mathematical one .A stabilization chart is obtained by repeating the analysis for increasing model order $\mathrm{n}$. The $\mathrm{X}$ axis is frequency and $\mathrm{Y}$ axis is the solution iteration number.

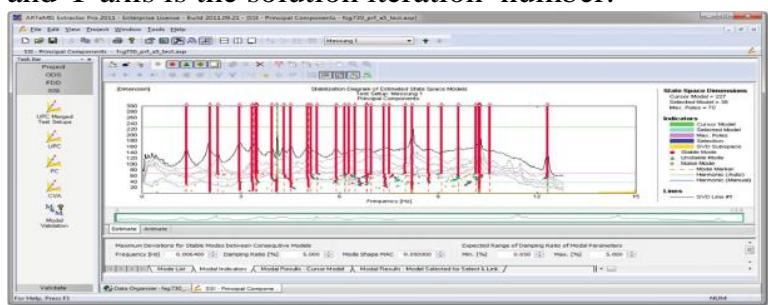

Fig(5 )Stblization diagram to calculate eigen modes The measurements is disclose information of structural behavior of tool holder structure and the nature of the excitation, using short time recorders as in Fig.(6) this fig.display the auto spectrum in three direction plot,it is a powerfull first indicator of structural modes and harmonic components.

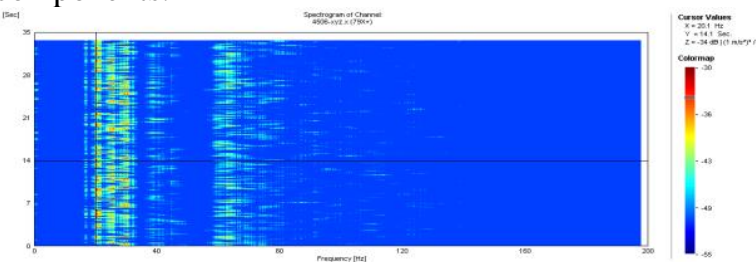

Fig(6) Short time fourier transformation STFT contor plot of response for $200 \mathrm{~Hz}$ range frequency and $35 \mathrm{sec}$ recording.
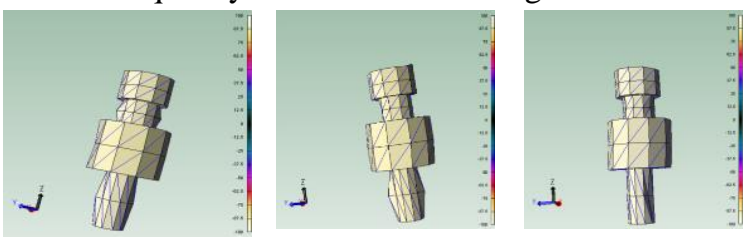

Fig,(7) Sample of experimental Mode shape of tool holder
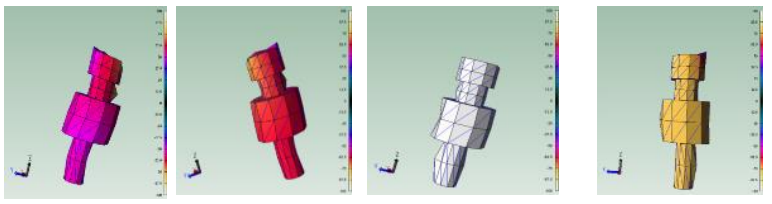

All modes for its bending modes expect last mode (8) its complex between bending and torsion)

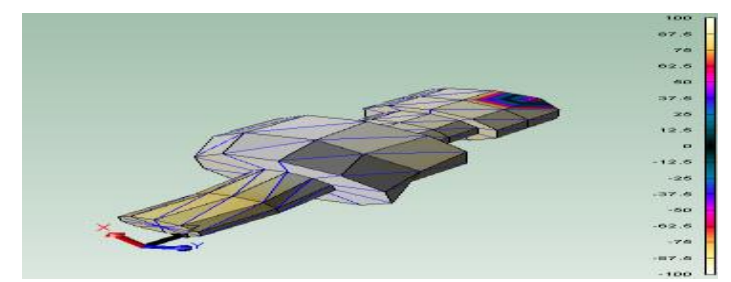

The results of measured mode are representation of complex modes of the tool holder's vibration pattern at a given resonant frequency. The modes that closer in frequency contribute more to imaginary part of complex mode than those lying far away, these results are verified in[18].

\section{FE MODELING}

The geometrical model of the tool holder is shown in Fig.( 1) after modeling selection ,the input data as material properties such as modulus of elasticity, Poisson ratio, and density are applied Material properties of the tool holder (steel) Young's modulus, $\mathrm{E}$ (MPa) 2E3Density, (N. $\left.\sec ^{2} / \mathrm{mm}^{4}\right)$ 2.849E7Poisson's ratio, 0.3The elements used in FEM model for mesh generation are quadratic tetrahedral element as in Fig.(8), modal analysis has been done to obtain natural frequencies and mode shape to match natural frequencies and mode shapes and to find time consuming when damping ratio is constant .to make a FEM model, a three dimensional geometrical model of tool holder has been formatted using ANSYS soft ware the mode Shape as in Fig.(9). Damping ratio $=0.089$

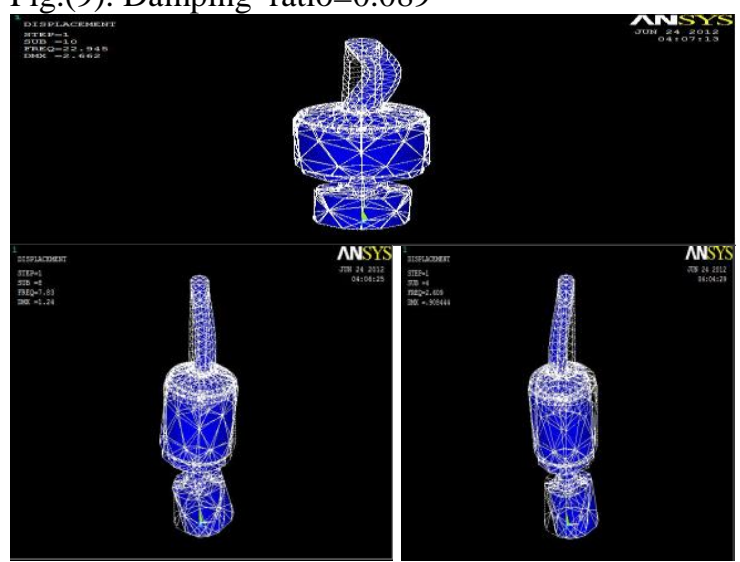


Fig(8)Mesh generation Eigen modes of tool holder calculated by FE Using ANSYS results .
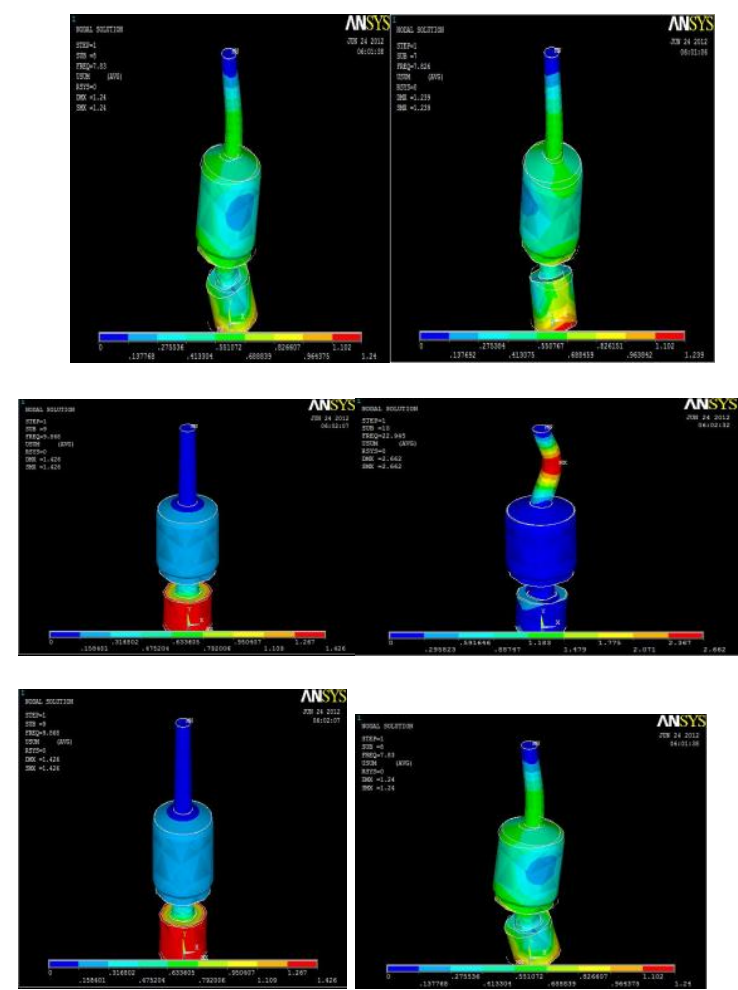

Fig.( 9)Selected mode shape of tool holder by FE analysis

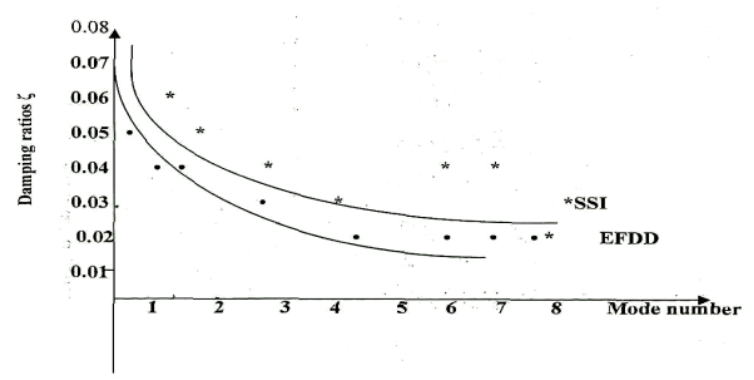

Fig.(10)Damping ratio of the first eight modes shapes for two techniques

In the attempt to work with reduced models, the partitioned Eq.(5) is used. The original system with 20 finite elements has an order of $80 \times 80$ As three accelerometers were used in the positions mentioned previously, the reduced system has an order of $3 \times 3$.To create reduced mass and stiffness matrices.

\section{RESULTS AND DISCUSSION}

In order to prove the applicability of the proposed model, two techniques were used to find the dynamic behavior of tool holder. The main goal is to establish the damping matrix of the system for high order. The basic procedure involves the mathematical modeling of the system (finite element method) mode shape as shown in Fig.(9), modal analysis (Eigen data), iterative technique[14] to reduce the system order and the estimate the system damping matrix. From Fig.(10) we notice that damping ratio decreases with increasing mode order, this result can be used for design tool holder . For experimental data three accelerometers were used, the system was excited though an impact hammer and exciter. The damping ratios were estimated using EFDD and SSI[15,16]. The results obtained from the experimental EFDD and SSI are similar. The measured damping ratios were applied in equation (6) to estimate damping constants $\mathrm{a}_{1}, \mathrm{a}_{2}, \mathrm{a}_{3}, \mathrm{a}_{\mathrm{n}}$ for selected high order. Finally, a proportional damping matrix was adjusted ; with saving time. Then Eigen value analysis matrices are of size $2 n \times 2 n$ instead of $n \times n$ for $n$ degrees of freedom. . This fact introduced damping matrix serves as an initial reference for the simulation of the system dynamical behavior.

\section{CONCLUSION}

This paper presents a new approach in designing tool holder that is subjected to dynamically induced load. Using empirical efficient model for the tool-holder dynamics. The modal damping in structure has been described and validated using two methods. These methods calculate an approximate proportional damping matrix which allows solving dynamic analyses using modal superposition techniques with real modes in high frequency modes. EFDD and SSI are accurate methods for identification damping ratios . These methods can be used to monitor instantaneous damping behavior and modal parameters during operation. It opens the possibility of conducting health monitoring during operation. The use of this methodology, gives the design engineer the ability to investigate the response of large structural in wide range in degrees of freedom.

The main advantages of the proposed new methods are simplicity and saving in computation time to solve complex modes. Eigen value analysis matrices are of size $2 n \times 2 n$ instead of $n \times n$ for $n$ degrees of freedom, which increases computation time very rapidly also uses real mode superposition techniques. Additionally, the degree of accuracy in identifying resonance frequencies and mode shapes of tool holder.

\section{REFERENCES}

[1]Y. Altintas and Philip K. Chan. In-process detection and suppression of chatter in milling. International Journal of Machine Tools and Manufacture, 32(3):329 - 347, 1992.

[2] davies m. a., pratt j. r., dutterer b. s., burns t. J.: , Chatter Recognition and Control System. Manufacturing Laboratories, Inc. Gainesville. Florida, U.S., 1992, patent nr 5170 358; 117123 ; 
[3] F. Ismail and R. Ziaei. Chatter suppression in five-axis machining of flexible parts. International Journal of Machine Tools and Manufacture, 42(1):115 - 122, 2002.

[4] Emad Al-Regib, Jun Ni, and Soo-Hun Lee.Programming spindle speed variation for machine tool chatter suppression. International Journal of Machine Tools and Manufacture, 43(12):1229 - 1240, 2003.

[5] Amir Rashid and Cornel Mihai Nicolescu. Design and implementation of tuned viscoelastic dampers for vibration control in milling. International Journal of Machine Tools and Manufacture, 48(9):1036 - 1053, 2008.

[6] Jeffrey L. Dohner, James P. Lauffer, Terry D. Hinnerichs, Natarajan Shankar,Mark Regelbrugge, Chi-Man Kwan, Roger Xu, Bill Winterbauer, and Keith Bridger. Mitigation of chatter instabilities in milling by active structural control.Journal of Sound and Vibration, 269(1-2):197 - 211, 2004.

[7] Amir Rashid and Cornel Mihai Nicolescu. Active vibration control in palletized workholding system for milling. International Journal of Machine Tools and Manufacture, 46(1213):1626 - 1636, 2006.

[8] B. Denkena, F. Hackeloeer, and C. Neuber. 5-Dof harmonic frequency control using contactless magnetic guides.CIRP Journal of Manufacturing Science and Technology, 01/2009 2(1)21-28

[9] M.A. Alfares, A. Elsharkawy, Effects of axial preloading of angular contact ball bearings on the dynamics of a grinding machine spindle system, Journal of Materials Processing Technology 136 (1-3) (2003) 4859.

[10] S.A. Spiewak, T. Nickel, Vibration based preload estimation in machine toolspindles, International Journal of Machine Tools and Manufacture 41 (4) (2001) 567-588

[11] B. Bossmanns, J.F. Tu, A thermal model for high speed motorized spindles, International Journal of Machine Tools and Manufacture 39 (9) (1999) 1345- 1366.

[12] B.R. Jorgensen, Y.C. Shin, Dynamics of spindle-bearing systems at high speeds including cutting load effects, Journal of Manufacturing Science and Engineering 120 (1998) 387-394.

[13]M. Rantatalo, J. Aidanpa, B. G* ransson, P. Norman, Milling machine spindle analysis using FEM and non-contact spindle excitation and response measurement, International Journal of Machine Tools and Manufacture 47 (2007) 1034-1045.

[14]A.Alipour and F.Zareian Study Rayleigh damping structure; uncertainties and Treatments
World Conference on Earthquake Engineering October 12-17, 2008, Beijing, China

[15] D.F. Pilkey, Computation of a damping matrix for finite element model updating, Ph.D. Thesis, Virgin Polytechnic Institute and State University, 1998.

[16]S.Adhikari, Damping models for structural vibrations,Ph.D.Thesis, CambridgUniversity, (2000).

[17]Rudinger, F, Modelling and Estimation of Damping in Non- liner Randam vibration, Ph,D Thesis, Technical Universiyt of Denmark, Mechanical Engineering Department,(2002.)

[18] Chowdhury I., Dasgupta S., Computation of Rayleigh Damping Coefficients for Large Systems, The Electronic Journal of Geotechnical Engineering, Volume 8, Bundle c (2003).

[19]Van Overschee P., De Moor B., Subspace Identification for Linear Systems: heory, Implementation, Applications, Kluwer Academic Publishers, 1996, 254 p.

[20] N.M.M. Maia, Extraction of valid modal properties from measured data in structural vibrations, Ph.D. Thesis University of London, 1988.

[21]A.M. Iglesias, Investigating various modal analysis extraction techniques to estimate damping ratio, Master thesis Virginia Polytechnic Institute State University, 2000.

[22]M.I. Friswell, S.D. Garvey, J.E.T. Penny, Model reduction using dynamic and iterated IRS techniques, J. Sound Vib.186 (2) (1995) 311323.

[23].Peeters B, De Roeck G (1999) Reference-based stochastic subspace identification for outputonly modal analysis. Mechanical System Signal Processing 13(6):855-878

[24]Gomaa, F.1, Ta yel, M.2, Kandil, K.3, Hekal, G.4 Validation Study Illustrates the Accuracy of Operational Modal Analysis Identification International Journal of advanced Engineering Technology 2250-2459, Volume 2, Issue 11, November 2012).

[25]Brincker,R.and ndersen, P Understanding stochastic subspace identification.Proceedings of the 24th International Moda Analysis Conference (IMAC), St.Louis, Missouri. 2006

[26]Mehd Batal,Svend Gade,Nis Moller, Henrik Herlusfsen Bruel\&Kjaer Sound \&Vibration Measurement A/S,Denmark, Ambint Response Modal Analysis on A Plate Structure. IMAC. XI Conference.2011 (11page)

[27] Batal,M.," Operational Modal Analysis Another way of Doing Modal Testing",Sound and vibration, August, 2002. (22-27)

[28] Brincker,R., Zhang,L. and Anderson, P,:'Modal Identification of Output-Only Systems Using 
Frequency Domain Decompostion"; Instute of Publishing, Smart materials and structures, 10, 2001,441-445.

[29] Brincker,R.,Zhang,L. and Anderson, P,:'Output- Only Modal Analysis By Frequency Domain Decomposition" Proceeding of ISMA International Conference on Noise and vibration Engineering25, 2000- Volume2.

[30] Filipe Magalhães $A^{\prime}$ lvaroCunha a, ElsaCaetano a, RuneBrincker Damping estimation using free decays and ambient vibration Mechanical Systems and signal processing 24 (2010) 127-419. 